\title{
The potential of biocarbon as $\mathrm{CO}_{2}$ adsorbent in VPSA unit
}

\author{
Izabela Majchrzak-Kucęba ${ }^{1} \cdot$ Marcelina Sołtysik $^{1}$
}

Received: 14 September 2019 / Accepted: 16 May 2020 / Published online: 5 June 2020

(c) The Author(s) 2020

\begin{abstract}
The best solution to the main environmental problem seems to be $\mathrm{CO}_{2}$ capture to reduce greenhouse gas emissions. The activated carbons derived from biomass have attracted extensive attention as solid adsorbent for carbon dioxide capture process. In this work, we focus on examining the properties of biochar (non-activated porous carbon) produced from biomass. Physicochemical properties of the biochar were investigated by thermogravimetric analysis (TG), Fourier transform infrared spectroscopy, scanning electron microscopy and $\mathrm{N}_{2}$ adsorption-desorption at $77 \mathrm{~K}$. In order to evaluate the possibility of using biocarbons for $\mathrm{CO}_{2}$ adsorption in large-scale VPSA units, investigations of these adsorbents in laboratory are necessary. The paper present the potential of biochar for $\mathrm{CO}_{2}$ capture in VPSA unit. The examination of the $\mathrm{CO}_{2}$ sorptive capability, stability and regeneration performance of biochar was carried out using a Mettler-Toledo TGA/SDTA 851e thermobalance and TG-Vacuum system. The sorption of $\mathrm{CO}_{2}$ was carried out isothermally in a flow of a mixture of gasses: $\mathrm{CO}_{2}(100$ vol.\%) and $\mathrm{CO}_{2}(16 \mathrm{vol} . \%) / \mathrm{N}_{2}(84 \mathrm{vol} . \%)$. The commercial biochar showed a sorption performance for $\mathrm{CO}_{2}$ up to $26.4 \mathrm{mg} \mathrm{CO}_{2} \mathrm{~g}^{-1}$ adsorbent at $30^{\circ} \mathrm{C}$ and 30 bar. Repeated use of the adsorbent in the sorption/desorption cycle did not affect its performance, which indicates high sorption stability.
\end{abstract}

Keywords Biocarbon $\cdot$ Carbon dioxide $\cdot$ Adsorption $\cdot$ TG-Vacuum $\cdot$ VPSA

\section{Introduction}

Carbon dioxide emissions resulting from the burning of fossil fuels and industrial activities are now the main cause of adverse changes in the atmosphere. As a result of higher energy demand, the level of carbon dioxide emissions in the world has reached a record level in history-37 billion tonnes in 2018 [1]. From the analysis of the carbon balance in the biosphere, it is clear that there is an incredible variation between carbon dioxide emission in the form of carbon dioxide to the atmosphere and its assimilation by sources on Earth [2]. The reduction in greenhouse gas emissions, including $\mathrm{CO}_{2}$, is now becoming the main goal of the European Union. Among the currently available methods, post-combustion $\mathrm{CO}_{2}$ capture plays a leading role due to the possibility of modernization of already existing power plants [3]. The method of post-combustion $\mathrm{CO}_{2}$ capture includes

Izabela Majchrzak-Kucęba

izak@is.pcz.czest.pl

1 Faculty of Infrastructure and Environment, Institute of Advanced Energy Technologies, Czestochowa University of Technology, Czestochowa, Poland absorption by aqueous solutions, adsorption by solid materials and membrane separation. Among them, the adsorption method is advantageous due to the low energy consumption and easy regeneration of the adsorbent, without producing adverse by-products or contaminated sorbents [4-7]. Activated carbon, zeolites and metal-organic frameworks (MOFs) are carbon dioxide capture adsorbents described in the literature [8-14]. Potential adsorbents for $\mathrm{CO}_{2}$ capture are also porous carbon obtained from biomass, so-called biochar and biocarbon [15]. Although zeolites and MOFs have a high $\mathrm{CO}_{2}$ adsorption capacity, it decreases in the presence of water [16]. In contrast, activated carbon is hydrophobic and has a large surface area and excellent thermal and chemical stability. In addition, it is possible to optimize the pore size of activated carbon materials for high $\mathrm{CO}_{2}$ adsorption. Therefore, they should be considered as potential adsorbents for VPSA $\mathrm{CO}_{2}$ capture systems. Another advantage of using biocarbon as a $\mathrm{CO}_{2}$ adsorbent is its low cost. It is know that the overall cost of $\mathrm{CO}_{2}$ capture could be reduced significantly by using inexpensive carbon precursors and minimizing the number of steps involved in the synthesis procedure [4]. The type of porous carbon precursor used and the preparation method have a significant impact on the structure and 
porosity of the obtained porous carbon $[17,18]$. European standards condition the production of biocarbon only in the process of pyrolysis of biomass (or identical substrate) in a temperature regime from 350 to $1000{ }^{\circ} \mathrm{C}$, in an anaerobic atmosphere (or in the presence of a small amount of oxygen) in the pyrolysis chamber $[19,20]$. According to many researchers [21-23], biochar needs to be activated to generate high surface area and porosity before being employed for $\mathrm{CO}_{2}$ capture. Scientists are focusing on the modification of biochar, mainly with chemical agents, e.g., $\mathrm{KOH}, \mathrm{K}_{2} \mathrm{CO}_{3}$, which affect their structure. Most studies focus on biocarbons after activation (chemically modification) [21-23]. However, the use of chemicals in the adsorbent activation process contributes to increasing environmental pollution. There is hardly any information in the literature related to uses of biochar (non-activated porous carbon) in VPSA $\mathrm{CO}_{2}$ capture unit. Therefore, in the present article, the $\mathrm{CO}_{2}$ sorption capacity and biochar stability in multiple cycles was determined using thermogravimetric methods. We focused on the possibility of using biochar in VPSA installations, assessing their performance in the simulation process in the TG-Vacuum installation.

\section{Method and materials}

\section{Materials characterization}

The biocarbon from company Fluid S.A. was used in this study. Fluid S.A. technology is the most energy-efficient technology of biocarbon production [24]. The slow carbonization technology, which they use, directly leads to biocarbon production, where the products are mainly biocarbon (65-80\%) and process gases (15-35\%). It consists in thermal processing of plant biomass and other biomass residues through its autothermal roasting at a temperature higher than $260{ }^{\circ} \mathrm{C}$ in anaerobic atmosphere.

\section{Characteristics of research methods}

A LECO Truspec CHNS analyzer was used to ascertain the amount of carbon, nitrogen, hydrogen and sulfur in the biocarbon. The Zeiss Merlin scanning electron microscope (SEM) was used to record the field emission SEM images. The textural parameters and porosity of the materials were investigated with a $\mathrm{N}_{2}$ sorption analyzer (Micromeritics Gemini 2360). Samples were degassed overnight at a set temperature of $250{ }^{\circ} \mathrm{C}$ prior to analysis, which was carried out at $-196{ }^{\circ} \mathrm{C}$. The specific surface area was calculated using the Brunauer-Emmett-Teller (BET) method from the linear part of BET plot according to IUPAC recommendations using the adsorption isotherm (relative pressure $\left(p / p_{\mathrm{o}}\right)=0.05-0.23$ ). The pore size distribution was calculated by the BJH method, and the pore volume was obtained from the maximum amount of adsorption at $\mathrm{p} / \mathrm{p}_{\mathrm{o}}$ of 0.99 . The FTIR spectra were recorded on a Nicolet 6700 spectrometer. The tablet preparation consisted of mixing $0.01 \mathrm{~g}$ of test material and $0.2 \mathrm{~g}$ of $\mathrm{KBr}$ powder. The thermal stability of sorbents was tested using a thermobalance TGA/SDTA 851e. Argon was used as the furnace medium, which was supplied into the analyzer furnace at a flow rate of $200 \mathrm{~mL} \mathrm{~min}^{-1}$ within the temperature range. The stand for conducting research on the adsorption/ desorption process using a vacuum consists of TGA/SDTA 851e thermobalance (TG) from Mettler-Toledo and a specially selected vacuum set.

\section{Tests of $\mathrm{CO}_{2}$ sorption capacity}

The physicochemical properties of the commercial biocarbon and their $\mathrm{CO}_{2}$ sorption/desorption capacities were examined using thermogravimetric methods. In the programmed adsorption test, the sample was first dried at 120 ${ }^{\circ} \mathrm{C}$ under a stream of nitrogen $\left(100 \mathrm{~mL} \mathrm{~min}^{-1}\right)$ for $30 \mathrm{~min}$, and then, the sample was cooled to $25^{\circ} \mathrm{C}$ to initiate the $\mathrm{CO}_{2}$ adsorption process. The adsorption process was carried out in a gas atmosphere containing $100 \mathrm{vol} . \% \mathrm{CO}_{2}$ and 16 vol.\% $\mathrm{CO}_{2} / 84$ vol. $\% \mathrm{~N}_{2}$. The sample was kept under test conditions until it reached the adsorption balance, which lasted $60 \mathrm{~min}$. Figure 1 shows road of carbon dioxide adsorption study. Research of adsorption-desorption cycles using thermobalance TGA/SDTA 851e was also carried out. The $\mathrm{CO}_{2}$ flow rate was set at $100 \mathrm{~cm}^{3} \mathrm{~min}^{-1}$, while the desorption process was conducted in an anaerobic atmosphere.

Low-pressure $\mathrm{CO}_{2}$ adsorption experiments were carried out using a TG-Vacuum instrument fitted. TG-Vacuum system was used to obtain information about the usefulness of adsorbent for testing at the VPSA pressure swing adsorption plant. Prior to $\mathrm{CO}_{2}$ adsorption measurements, the samples were put on overnight degassing under vacuum at $200{ }^{\circ} \mathrm{C}$. Adsorption of $\mathrm{CO}_{2}$ was carried out at atmospheric pressure, while during desorption it was $30 \mathrm{kPa}$ abs. A single-cycle adsorption/desorption endures $15 \mathrm{~min}$. The test conditions are presented in Table 1.

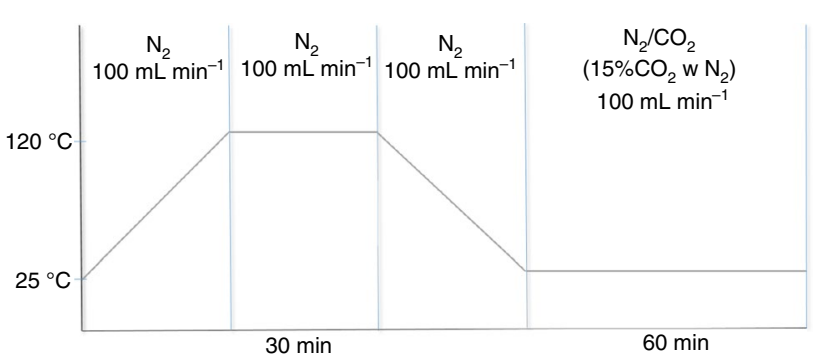

Fig. 1 Diagram of the road of carbon dioxide adsorption study 
Table 1 Parameters for conducting sorption/desorption tests

\begin{tabular}{lllll}
\hline Material & $\begin{array}{l}\text { Sorption tem- } \\
\text { perature }\left(\mathrm{CO}_{2}\right. \\
\text { atmosphere }) /{ }^{\circ} \mathrm{C}\end{array}$ & $\begin{array}{l}\text { Desorption } \\
\text { temperature }\left(\mathrm{N}_{2}\right. \\
\text { atmosphere }) /{ }^{\circ} \mathrm{C}\end{array}$ & $\begin{array}{l}\text { Number } \\
\text { of cycles }\end{array}$ & $\begin{array}{l}\text { Duration } \\
\text { of cycles/ } \\
\text { min }\end{array}$ \\
\hline $\begin{array}{c}\text { Biocar- } \\
\text { bon }\end{array}$ & 30 & 30 & 4 & 15 \\
\hline
\end{tabular}

\section{Physicochemical characterization of the biocarbon}

As shown in Table 2, the biocarbon used in this study contains a large amount of carbon $(91.56 \%$ by mass) and a small amount of nitrogen $(0.73 \%$ by mass) based on CNS elemental analysis. The presence of sulfur in the material was not detected. The carbon content of the biocarbon is a measure of the degree of carbonization. Prior to weighing and analysis, the samples were dried in an oven and stored in a desiccator. Elemental analysis was measured in triplicate. It is known that [4] during carbonization, the $\mathrm{C}$ content increased considerably, and the $\mathrm{O}$ and $\mathrm{N}$ content decreased due to the evaporation of hydrogen, nitrogen and oxygen in the gas phase.

The high elemental carbon content $(91.6 \%)$ reduces the elasticity of the molecular phase of the material structure, resulting in a simultaneous increase in the degree of cross-linking of the macromolecular phase. Carbon and its derivatives with a high elemental carbon content contain a macromolecular phase with limited stiffness, which means that the porous carbon mass can be expanded when placing molecules in submicropores smaller than the size of sorbate molecules [25]. According to the literature data, efficient $\mathrm{CO}_{2}$ adsorption on carbon materials is closely related to the high content of carbon as well as nitrogen in their composition. Although the nitrogen content naturally found in this type of material is usually low, it can be incorporated into the structure by inter alia with ammonia [26]. The introduction of nitrogen into the material structure is to allow effective development of the porous surface [27, 28]. Research conducted by Madzaki et al. proves that the high nitrogen content does not reflect the adsorption capacity of $\mathrm{CO}_{2}$. Carbon materials enriched in nitrogen and equivalents without the admixture of a nitrogen adsorption values were comparable $\mathrm{CO}_{2}$. Carbon dioxide capture by carbon materials and their counterparts additionally enriched with nitrogen was at the same level [29]. Fourier transform infrared spectroscopy
(FTIR) is frequently used to identify functional groups in biocarbon. FTIR analysis requires special sample preparation, because biocarbon is opaque solid. Figure 2 shows FTIR spectra of the used in this study biocarbon. Important and strong extended absorption peak at $3400 \mathrm{~cm}^{-1}$ spectra is the $\mathrm{O}-\mathrm{H}$ and $\mathrm{H}-\mathrm{O}-\mathrm{H}$ stretch. Poorly visible peaks at 3000-2860 $\mathrm{cm}^{-1}$ are associated with the alphatic $\mathrm{C}-\mathrm{H}$ stretch, aromatic $\mathrm{C}-\mathrm{H}$ bond $\left(3060 \mathrm{~cm}^{-1}\right)$ and carboxylic stretch $\mathrm{C}=\mathrm{O}\left(1700 \mathrm{~cm}^{-1}\right)$. Other stretching bands can be observed in the FTIR spectra of the around $930 \mathrm{~cm}^{-1}(\mathrm{C}-\mathrm{CO}$ groups) and with similar trend observed in the range 1410 $\mathrm{cm}^{-1}$ due to $\mathrm{C}-\mathrm{H}$ bending [30-32].

The SEM technique was used to analyze the surface morphology of the biochar. Figure 3 shows the SEM micrographs of the biocarbon sample.

The SEM images of the sample in Fig. 3 reveal the presence of abundant pores. A large morphological diversity of the material is visible. The biocarbon sample shows irregular (non-uniform) structure pores. The recorded axial image of commercial biocarbon on the right in Fig. 3 clearly indicates that it is hardwood [33]. Two types of pores are shown: tracheids and rays. The rays run perpendicular to the tracheids and are vertical elements of the structure. The image on the left shows the transverse walls, where the porous plates that divide the concentrated vessels are visible. Table 3 summarizes the parameters of the biochar structure.

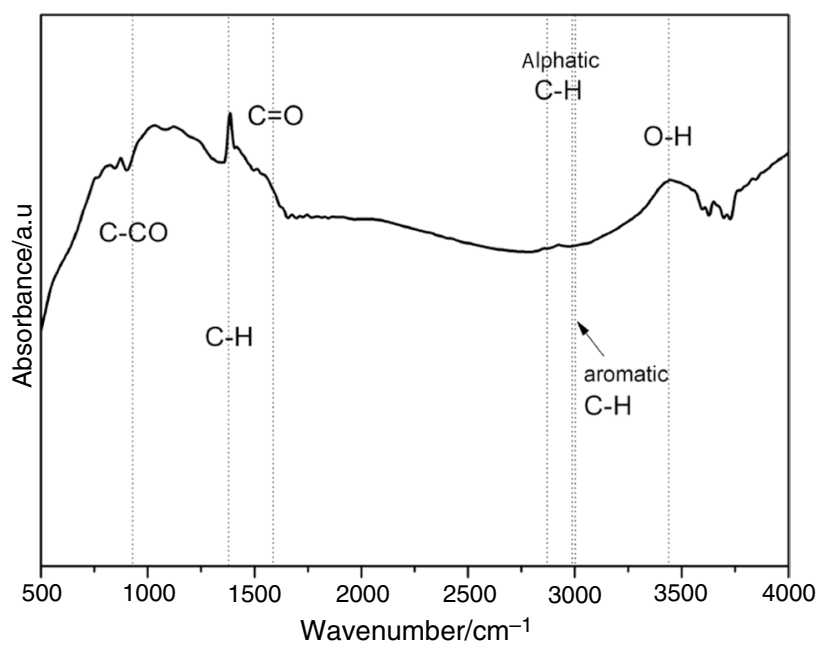

Fig. 2 FTIR spectra of the commercial biocarbon
Table 2 Content of carbon, hydrogen, nitrogen and oxygen in the biocarbon

\begin{tabular}{|c|c|c|c|c|c|c|c|c|}
\hline \multirow[t]{3}{*}{ Material } & \multicolumn{8}{|c|}{ Element } \\
\hline & \multicolumn{2}{|l|}{$\mathrm{C}$} & \multicolumn{2}{|l|}{$\mathrm{H}$} & \multicolumn{2}{|l|}{$\mathrm{N}$} & \multicolumn{2}{|l|}{$\mathrm{O}$} \\
\hline & mass $\%$ & SD & mass $\%$ & SD & mass\% & SD & mass\% & SD \\
\hline Biocarbon & 91.56 & 0.58 & 1.43 & 0.24 & 0.73 & 0.05 & 6.28 & 0.03 \\
\hline
\end{tabular}


Fig. 3 SEM photographs of biocarbon

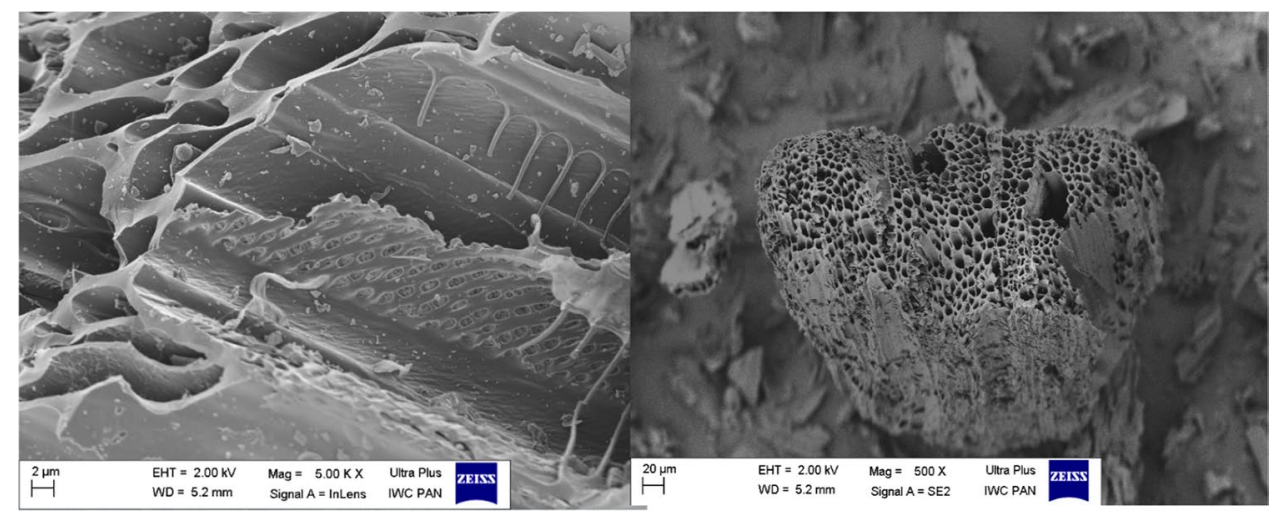

The biochar was composed entirely of pores about 4.74 $\mathrm{nm}$ (average pore diameter), which presented the surface area only $65 \mathrm{~m}^{2} \mathrm{~g}^{-1}$. The char has higher carbon content, the

Table 3 Parameters of the porous structure of the biocarbon by the BET method

\begin{tabular}{llll}
\hline Type of material & $\begin{array}{l}\text { Specific surface } \\
\text { area } \mathrm{S}_{\mathrm{BET}} / \mathrm{m}^{2} \\
\mathrm{~g}^{-1}\end{array}$ & $\begin{array}{l}\text { Total pore vol- } \\
\text { ume/ } / \mathrm{cm}^{3} \mathrm{~g}^{-1}\end{array}$ & $\begin{array}{l}\text { Average pore } \\
\text { diameter/nm }\end{array}$ \\
\hline Biocarbon & 65.00 & 0.04 & 4.74 \\
\hline
\end{tabular}

surface area of char is rather low due to the blockage of the pores by tars [4]. Similar values of biochar specific surface area can be found in the literature: $26.3 \mathrm{~m}^{2} \mathrm{~g}^{-1}$ [34], 38-92 $\mathrm{m}^{2} \mathrm{~g}^{-1}$ [35] and $115 \mathrm{~m}^{2} \mathrm{~g}^{-1}$ [4]. The small specific surface area of biocarbon $65 \mathrm{~m}^{2} \mathrm{~g}^{-1}$ does not necessarily mean low adsorption. The adsorption itself depends on many factors such as the presence of functional groups, pore structure or surface chemistry [36].

The low-temperature nitrogen adsorption/desorption isotherm for biocarbon can be classified according to the IUPAC classification [37] as type IV isotherm Adsorption/ desorption isotherms overlap perfectly. As follows from the analysis of nitrogen adsorption-desorption isotherms (Fig. 4), the biochar is characterized by poorly developed porosity. Insignificant adsorption is observed in the whole range of low relative pressures. The adsorption capacity of biochar is very low, indicating that not very many pores existed. The results are in accordance with pore size distribution and pore volume. Figures 5 and 6 show the shares of pores of specific sizes in the total specific surface area and total pore volume of biocarbon. Pores with a diameter of $2.04 \mathrm{~nm}$ have the largest share in the total specific surface area of biocarbon. The pores with a diameter of $22.9 \mathrm{~nm}$ have the largest share in the biocarbon pore volume.

Figure 7 shows the TG and DTG curves of the biocarbon in the temperature range of $25^{\circ} \mathrm{C} \div 800{ }^{\circ} \mathrm{C}$. The first loss of mass, caused by dehydration of moisture, existed between 30 ${ }^{\circ} \mathrm{C} \div 180^{\circ} \mathrm{C}$. The loss was caused by removing moisture from the sample. A net mass loss is $11 \%$. The second mass loss

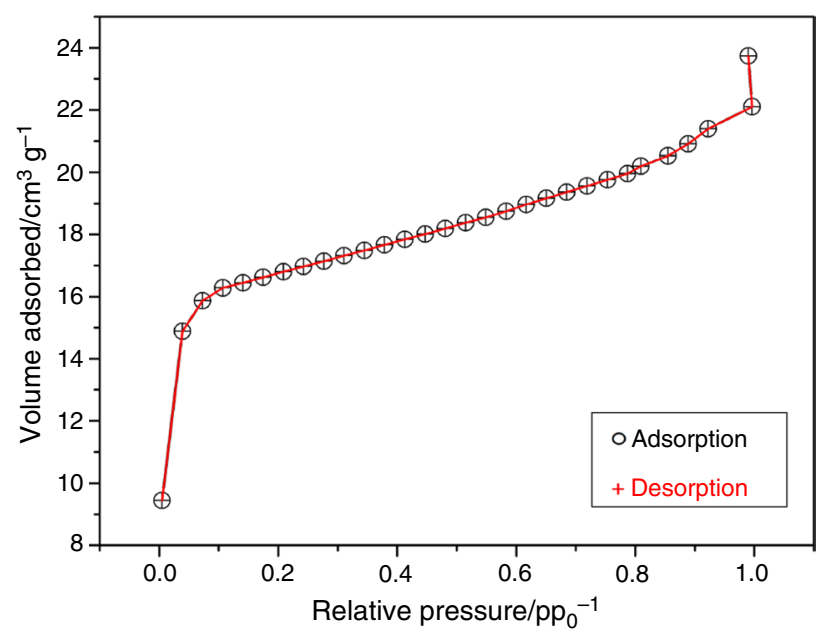

Fig. 4 Nitrogen adsorption-desorption isotherms of biocarbon

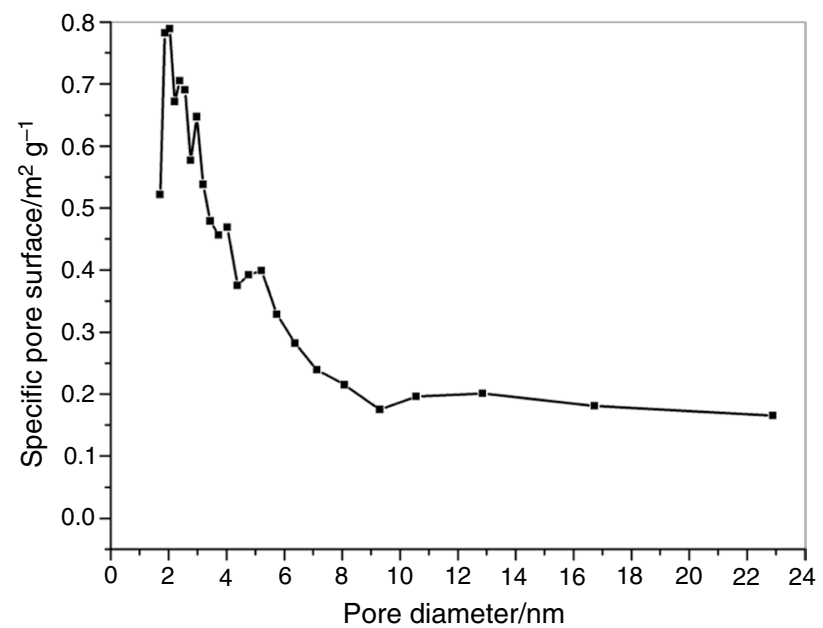

Fig. 5 Specific pore surface distribution as a function of the pore diameter for biocarbon 


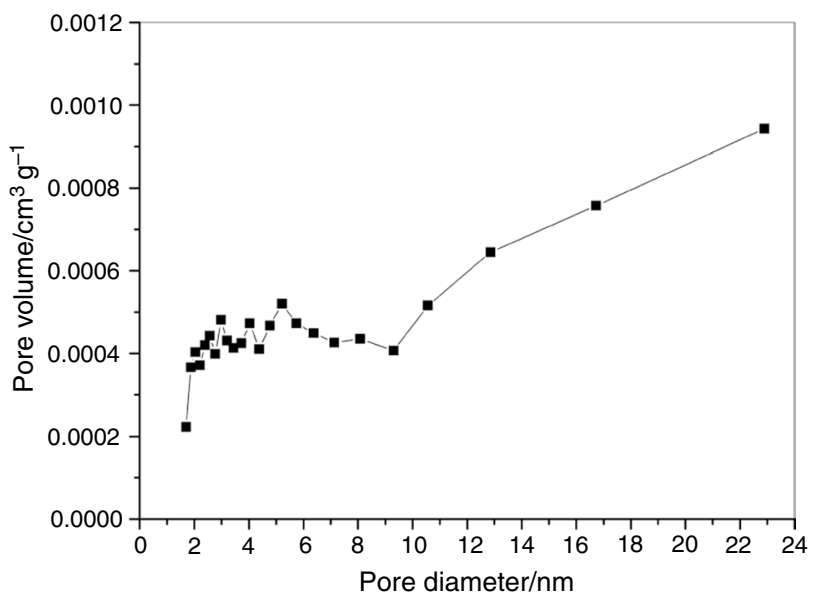

Fig. 6 Pore volume distribution as a function of the pore diameter for biocarbon

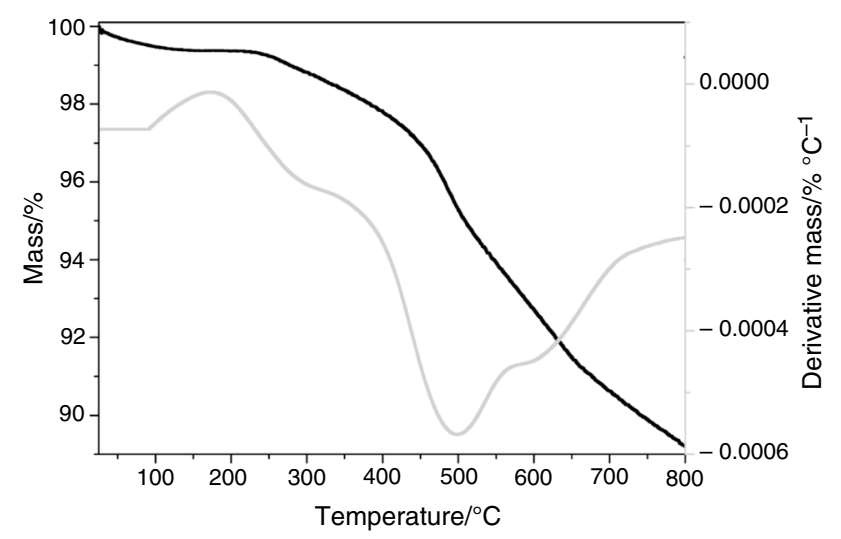

Fig. 7 TG and DTG curves of biocarbon

is due to devolatilization. The minimum of this peak for the biocarbon sample took place at $500{ }^{\circ} \mathrm{C}$. During this process, most elements other than carbon, hydrogen, nitrogen and oxygen are removed in gaseous form, leaving a solid residue enriched in carbon [4].

\section{Results}

\section{$\mathrm{CO}_{2}$ sorption capacity}

To determine the $\mathrm{CO}_{2}$ sorption capacity of the biocarbon, the first step was the temperature programmed adsorption test. This test was carried out according to the procedure shown in Fig. 1. Figure 8 shows the results of the programmed adsorption test for biocarbon.

Carbon dioxide adsorption capacity in the atmosphere of 100 vol. $\% \mathrm{CO}_{2}$ was higher and amounted to $26.4 \mathrm{mg} \mathrm{CO}_{2}$ $\mathrm{g}^{-1}$ adsorbent $\left(0.98 \mathrm{mmol} \mathrm{g}^{-1}\right)$. In an atmosphere of 16 vol.\% $\mathrm{CO}_{2}$ with $\mathrm{N}_{2}$ doping, it was $17.8 \mathrm{mg} \mathrm{CO}_{2} \mathrm{~g}^{-1}$ adsorbent $\left(0.66 \mathrm{mmol} \mathrm{g}^{-1}\right)$. The carbon dioxide capture efficiency of a biocarbon sample can be considered satisfactory given that it is a biocarbon sample without activation. Creamer et al. [38] studied $\mathrm{CO}_{2}$ adsorption on non-activated porous carbons prepared from sugarcane bagasse and hickory wood. According to [38] data, the $\mathrm{CO}_{2}$ sorption capacity of biochar was $73.55 \mathrm{mg} \mathrm{g}^{-1}$ and $35 \mathrm{mg} \mathrm{g}^{-1} \mathrm{CO}_{2}$ (depending on the conditions for obtaining biochar). Research conducted by Cramer et al. [38] proves that physisorption driven by weak van der Waals forces is the main operating mechanism for adsorption and the quadrupole nature of the $\mathrm{CO}_{2}$ molecule was put forward to be a useful attribute in creating a surface interaction with biochar via the process of dispersion and induction. According to the literature data [38], surface area was the main factor controlling the process of physisorption of $\mathrm{CO}_{2}$ onto biochar. The authors emphasized the role of the presence of nitrogen groups on the surface. According to Singh et al. [35], activated porous carbons are superior to biochars as they have higher specific surface areas and a more developed porosity, although biochars have their own advantage when it comes to the presence of abundant functional groups on the surface. The authors also stated that the nature and the quantity of the functional groups on the surface of carbon materials depend on the methods of preparation and the nature of the biomass precursors used [35].
Fig. 8 TG curves of sorption of $\mathrm{CO}_{2}$ (isothermally at $25^{\circ} \mathrm{C}$ ): a 100 vol. $\% \mathrm{CO}_{2} ; \mathbf{b} 16$ vol. $\% \mathrm{CO}_{2}$ and 84 vol. $\% \mathrm{~N}_{2}$

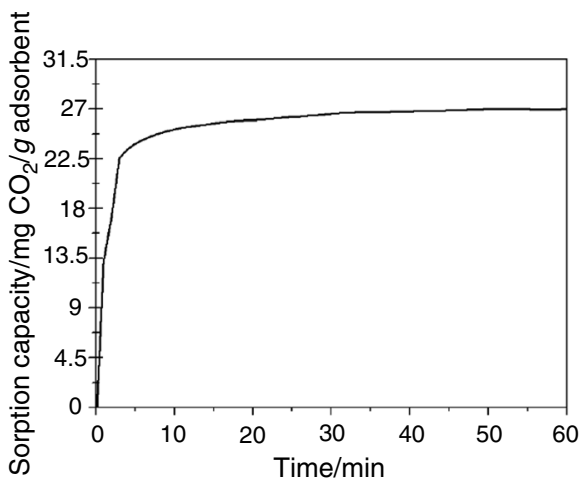

(a)

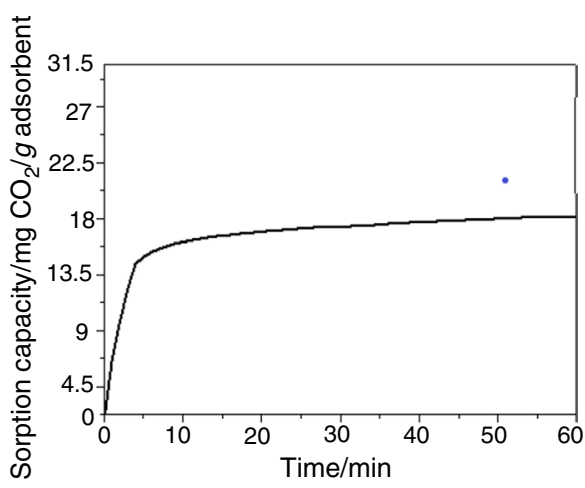

(b) 


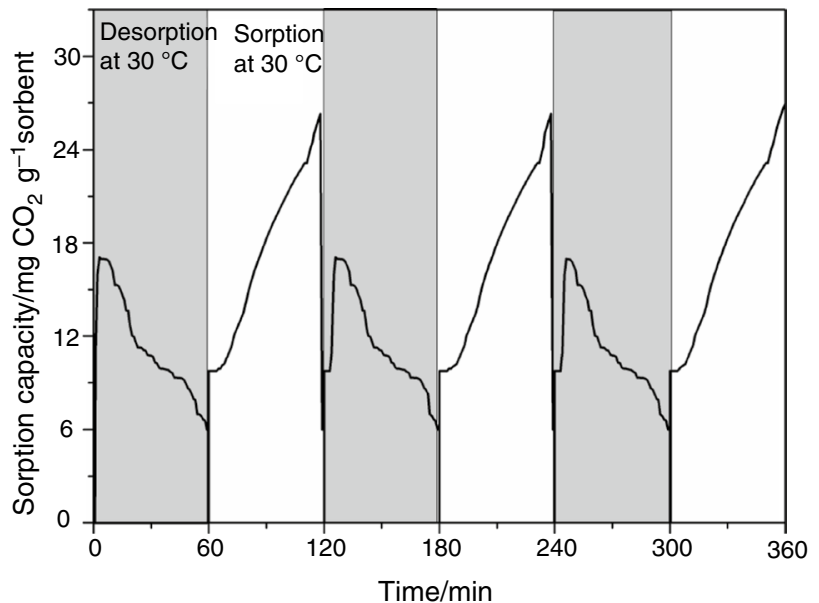

Fig. 9 TG profiles-multistage cyclic adsorption-desorption process for biocarbon (temperature sorption/desorption: $30{ }^{\circ} \mathrm{C}$; vacuum: 30 mbar)

\section{Test of pressure programmed desorption on TG-Vacuum}

The pressure programmed desorption test on TG-Vacuum was carried out with a view to further testing of the biochar on the VPSA adsorption installation. Figure 9 shows the TG curves obtained as a result of the programmed biocarbon desorption test.

When using pure $\mathrm{CO}_{2}$ the sorption capacity for biocarbon was $26.4 \mathrm{mg} \mathrm{CO}_{2} \mathrm{~g}^{-1}$ sorbent. As shown in Fig. 9, repeated use of the same sorbent did not significantly affect its sorption capacity. This confirms the good stability of the adsorbent and the possibility of using it in consecutive cycles. This aspect is very important from the position the practical use of the biocarbon in many $\mathrm{CO}_{2}$ sorption/desorption cycles. The working capacity of adsorbent in each cycle is the same.

\section{Conclusions}

In the article, we present the results of research carried out on commercial biochar obtained from the cutting of deciduous trees. Considering that the material has not been modified in any way, the test results are satisfactory. This gives hope for the possibility of using non-activated porous carbon obtained from biomass for carbon dioxide adsorption. The conducted analyzes showed that biocarbon can be used at temperatures around $25{ }^{\circ} \mathrm{C}$ (yield $0.98 \mathrm{mmol} \mathrm{g}^{-1}$ in 100 vol.\% $\mathrm{CO}_{2}$ ), which is beneficial from the point of view of the future use of this adsorbent in adsorption systems. The conducted studies of biocarbon regeneration under reduced pressure conditions confirmed the possibility of using this type of adsorbent in VPSA adsorption installations. The sorption capacity was $26.4 \mathrm{mg} \mathrm{CO} \mathrm{g}^{-1}$, additionally without losing its efficiency in repeated sorption/desorption processes. The porous structure of biochar and unique surface properties make it an effective $\mathrm{CO}_{2}$ adsorbent.

Acknowledgements This article has been supported by the Polish National Agency for Academic Exchange under Grant No. PPI/ APM/2019/1/00042. The scientific research was funded by the statute subvention of Czestochowa University of Technology, Faculty of Infrastructure and Environment.

Open Access This article is licensed under a Creative Commons Attribution 4.0 International License, which permits use, sharing, adaptation, distribution and reproduction in any medium or format, as long as you give appropriate credit to the original author(s) and the source, provide a link to the Creative Commons licence, and indicate if changes were made. The images or other third party material in this article are included in the article's Creative Commons licence, unless indicated otherwise in a credit line to the material. If material is not included in the article's Creative Commons licence and your intended use is not permitted by statutory regulation or exceeds the permitted use, you will need to obtain permission directly from the copyright holder. To view a copy of this licence, visit http://creativecommons.org/licenses/by/4.0/.

\section{References}

1. Energy and Climate Change. OECD/IEA. World Energy Outlook Special Report. https://www.iea.org/geco/emissions/.

2. Pawlak W. Turbulent exchange of carbon dioxide between the atmosphere and the urbanized area, agricultural area and wetland-the differences in the annual and diurnal variability. Sci Rev Eng Environ Sci. 2014;64:131-9.

3. Jiang L, Roskilly AP, Wang RZ. Performance exploration of temperature swing adsorption technology for carbon dioxide capture. Energy Convers Manag. 2018;165:396-404.

4. Luo L, Chen T, Li Z, Zhang Z, Zhao W, Fan M. Heteroatom self-doped activated biocarbons from fir bark and their excellent performance for carbon dioxide adsorption. J CO2 Util. 2018;25:89-98.

5. Querejeta N, Rubiera F, Covandoga P. Enhanced capacity to $\mathrm{CO}_{2}$ sorption in humid conditions with a K-doped biocarbon. J Energy Chem. 2019;34:208-19.

6. Liu X, Sun Ch, Liu H, Tan W, Wang W, Snape C. Developing hierarchically ultra-micro/mesoporous biocarbons for highly selective carbon dioxide adsorption. Chem Eng J. 2019;361:199-208.

7. Singh G, Kim IY, Lakhi KS, Srivastava P, Naidu R, Vinu A. Single step synthesis of activated bio-carbons with a high Surface area and their excellent $\mathrm{CO}_{2}$ adsorption capacity. Carbon. 2017;116:448-55.

8. Li D, Ma T, Zhang R, Tian Y, Qiao Y. Preparation of porous carbons with high low-pressure $\mathrm{CO}_{2}$ uptake by $\mathrm{KOH}$ activation of rice husk char. Fuel. 2015;139:68-70.

9. Chen J, Yang J, Hu G, Hu X, Li Z, Shen S, Radosz M, Fan M. Enhanced $\mathrm{CO}_{2}$ capture capacity of nitrogen-doped biomass-derived porous carbons. ACS Sustain Chem Eng. 2016;4(3):1439-45.

10. Shao L, Liu M, Huang J, Liu YN. $\mathrm{CO}_{2}$ capture by nitrogen-doped porous carbons derived from nitrogen-containing hyper-crosslinked polymers. J Colloid Interface Sci. 2018;513:304-13. 
11. Zukal A, Shamzhy M, Kubů ČJ. The effect of pore size dimensions in isoreticular zeolites on carbon dioxide adsorption heats. J CO2 Util. 2018;24:157-63.

12. Ke Q, Sun T, Wei $\mathrm{X}$, Guo $\mathrm{Y}$, Wang $\mathrm{S}$. Enhanced trace $\mathrm{CO}_{2}$ capture on heteroatom-substituted RHO zeolites under humid conditions. Chem Sustain Chem. 2017;10(21):4207-14.

13. Millward AR, Yaghi OM. Metal-organic frameworks with exceptionally high capacity for storage of carbon dioxide at room temperature. J Am Chem Soc. 2005;127(51):17998-9.

14. Dong L, Chen M, Li J, Shi D, Dong W, Li X, Bai Y. Metal-organic framework-graphene oxide composites: a facile method to highly improve the $\mathrm{CO}_{2}$ separation performance of mixed matrix membranes. J Membr Sci. 2016;520:801-11.

15. Duran J, Alvarez-Gutierrez N, Rubiera F, Pevida C. Biogas purification by means of adsorption on pine sawdust-based activated carbon: impact of water vapour. Chem Eng J. 2018;353:197-207.

16. Modak A, Jana S. Advancement in porous adsorbents for postcombustion $\mathrm{CO}_{2}$ capture. Microporous Mesoporous Mater. 2019;276:107-32.

17. Wang Q, Luo J, Zhong Z, Borgna A. $\mathrm{CO}_{2}$ capture by solid adsorbents and their applications: current status and new trends. Energy Environ Sci. 2011;4:42-55.

18. Himeno S, Komatsu T, Fujita S. High-pressure adsorption equilibria of methane and carbon dioxide on several activated carbons. J Chem Eng Data. 2005;50:369-76.

19. Lee SY, Park SJ. A review on solid adsorbents for carbon dioxide capture. J Ind Eng Chem. 2015;23:1-11.

20. Creamer AE, Gao B, Wang S. Carbon dioxide capture using various metal oxyhydroxide-biochar composites. Chem Eng J. 2016;283:826-32.

21. Correia LB, Fiuza RA Jr, de Andrade RC, Andrade HMC. $\mathrm{CO}_{2}$ capture on activated carbons derived from mango fruit (Mangifera indica L.) seed shells. J Therm Anal Calorim. 2017;131:579-86.

22. Tabak A, Sevimli K, Kaya M, Çă̆lar B. Preparation and characterization of a novel activated carbon component via chemical activation of tea woody stem. J Therm Anal Calorim. 2019;138:3885-95.

23. Giraldo L, Moreno-Piraján JC. $\mathrm{CO}_{2}$ adsorption on activated carbon prepared from mangosteen peel. J Therm Anal Calorim. 2018;133(1):337-54.

24. Gładki J. Biochar as a chance for sustainable development. Sędziszów-Kielce: Oficyna Poligraficzna Apla; 2017.

25. Baran P, Jodłowski GS, Wójcik M, Zarębska K. Application of MSW model to describe mine gases sorption on the basis of the selected coal samples from the Rybnik Coal Area. Przegląd Górniczy. 2015;71(2):10-9.

26. Plaza M, Pevida C, Arias B, Fermoso J, Rubiera F, Pis JJ. A comparison of two methods for producing $\mathrm{CO}_{2}$ capture adsorbents. Energy Proc. 2009;1:1107-13.
27. Pietrzak R, Nowicki P, Wachowska H. Ammoxidized active carbons as adsorbents for pollution from liquid and gas phases. Pol J Environ Stud. 2010;19:449-52.

28. Nowicki P, Pietrzak R, Dobkiewicz M, Wachowska H. The effect of ammoxidation proces on $\mathrm{NO}_{2}$ sorption abilities of active carbons. Acta Phys Pol A. 2010;118:493-9.

29. Madzaki H, KarimGhani WAWAB, Rebitanim NZ, Alias AB. Carbon dioxide adsorption on sawdust biochar. Proc Eng. 2016;148:718-25.

30. Poletto M, Zattera AJ, Santana RMC. Structural differences between wood species: evidence from Chemical composition, FTIR spectroscopy, and thermogravimetric analysis. J Appl Polym Sci. 2012;126:336-43. https://doi.org/10.1002/app.36991.

31. Maia BG, Fernandes CD, Angelo SJM, Gonçalves CA, Cabral CER, Checon FIC. One-step methodology for preparing physically activated biocarbon agricultural biomass waste. J Environ Chem Eng. 2019;7:103-13.

32. Ogungbenro AE, Quang DV, Al-Ali KA, Abu-Zahra MRM. Activated carbon from date seeds for $\mathrm{CO}_{2}$ capture applications. Energy Proc. 2017;114:2313-21.

33. Panshin A, de Zeeuw C. Textbook of wood technology: structure, identification, properties, and uses of commercial woods of the United States and Canada. 1980.

34. Skubiszewska-Zieba J, Charmas B, Kołtowski M, Oleszczuk P. Active carbons from waste biochars. Structural and thermal properties. J Therm Anal Calorim. 2017;130:15-24.

35. Singh G, Lakhi KS, Sil S, Bhosale SV, Kim IY, Albahily K, Vinu A. Biomass derived porous carbon for $\mathrm{CO}_{2}$ capture. Carbon. 2019;148:164-86.

36. Guo Y, Zhang H, Tao N, Liu Y, Qi J, Wang Z, Xu H. Adsorption of malachite green and iodine on rice husk-based porous carbon. Mater Chem Phys. 2003;82:107-15.

37. Thommes M, Kaneko K, Neimark AV, Olivier JP, RodriguezReinoso F, Rouquerol J, Sing KSW. Physisorption of gases, with special reference to the evaluation of surface area and pore size distribution (IUPAC Technical Report). Pure Appl. Chem. 2015;87(9-10):1051-69.

38. Creamer AE, Gao B, Zhang M. Carbon dioxide capture using biochar produced from sugarcane bagasse and hickory wood. Chem Eng J. 2014;249:174-9.

Publisher's Note Springer Nature remains neutral with regard to jurisdictional claims in published maps and institutional affiliations. 